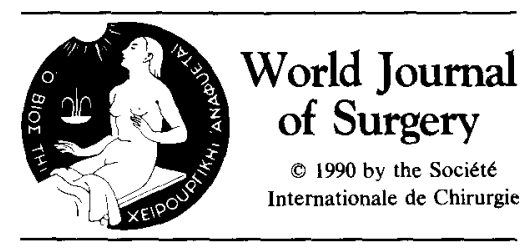

\title{
Assessment of Insertion Techniques and Complication Rates of Dual Lumen Central Venous Catheters in Patients with Hematological Malignancies
}

\author{
Ruud F.M. Jansen, M.D., Theo Wiggers, M.D., Bert N. van Geel, M.D., Wim L.J. van Putten, M.Sc. \\ Departments of Surgical Oncology and Statistics, Dr. Daniel den Hoed Cancer Center, Rotterdam, The Netherlands
}

\begin{abstract}
One hundred and twenty-three dual lumen silicone rubber central venous catheters were inserted into 101 patients with hematological malignancies undergoing intensive treatment. There was a perioperative complication rate of $13 \%$. Open and closed techniques for inserting the catheter were compared. The operating time needed for introducing the catheter by the closed technique (average, 51 minutes) was significantly shorter $(p<$ $0.001)$ than the time needed for the open technique ( 70 minutes), whereas complication rates were equal in both techniques. On average, the catheters functioned for 149 days. Complications leading to removal were observed in $29.3 \%$ of patients, most of which were catheter-related infections $(\mathbf{2 0 . 4 \% )}$. Thromboembolic complications leading to removal were less frequent $(4.1 \%)$ and appeared significantly earlier $(p<0.001)$. These data indicate that introduction of the catheter by direct puncture of the subclavian vein is a quick and safe technique, and that this type of catheter is suitable for long-term use, both for infusion and for blood sampling.
\end{abstract}

The intensive treatment of patients with hematological malignancies requires a reliable long-term central venous access. During the course of therapy, simultaneous infusion of chemotherapeutics, antibiotics, blood products including bone marrow, parenteral nutrients, and fluids is often necessary. Blood sampling for monitoring therapy and for bacteriological culture is very frequent.

To meet all these requirements, various types of indwelling catheters have been designed. Single [1, 2] and multiple lumen [3-6] catheters as well as totally implantable devices with subcutaneous access [7] are available. We prefer a dual lumen central venous catheter because it facilitates simultaneous infusion at a high flow rate [8] in combination with easy access to the system.

Long-term indwelling catheters in these immunocompromised and, at times, pancytopenic patients often leads to catheter-related complications $[1,6]$. The aim of this study was to investigate the technical aspects of the insertion technique and the function of the dual lumen catheter. Complication rates were also assessed.

Reprint requests: T. Wiggers, M.D., Department of Surgical Oncology, Dr. Daniel den Hoed Cancer Center, P.O. Box 5201, 3008 AE Rotterdam, The Netherlands.

\section{Material and Methods}

The records of all consecutive patients receiving a dual lumen central venous catheter from November, 1984 to January, 1987 were reviewed. All patients were presented to us by the Department of Hematology prior to undergoing intensive anticancer therapy, often including bone marrow transplantation. Seventy-five percent of the patients had acute leukemia (Table 1); patients were in all stages of their disease.

In all cases, a Hemed CVAC 420014.0 French silicone rubber dual lumen catheter (Gish Biomedical Inc., Santa Ana, California, U.S.A.) was used with an outer diameter of $4.5 \mathrm{~mm}$, each lumen having an internal diameter of $1.6 \mathrm{~mm}$. Its length is approximately $85 \mathrm{~cm}$ and it has a Dacron ${ }^{\circledR}$ cuff to obtain subcutaneous fixation and to act as a barrier to microorganisms. Ninety-two patients $(74.8 \%)$ received the catheter as the first long-term central venous catheter, $24(19.5 \%)$ as the second, 5 $(4.1 \%)$ as the third, and $2(1.6 \%)$ as the fourth catheter. When thrombocyte counts were below $45 \times 10^{9} / 1$, thrombocyte transfusions were given. Perioperative antibiotics were not administered.

All catheters were inserted under strict sterile conditions in the operating room, usually under local anesthesia. Most catheters were introduced through the open method, usually by a cut-down of the external jugular vein [9]. In the course of the study, this technique was largely replaced by direct puncture of the subclavian vein and introduction of the catheter through a peel-away sheath [10] (Table 2). All catheters were tunneled, placing the Dacron ${ }^{\mathbb{1}}$ cuff at the end of the $15-20-\mathrm{cm}$ long subcutaneous tunnel. Immediately after the procedure, an x-ray was made, to check for the position of the tip of the catheter and to rule out pneumothorax. Complications of the procedure were noted: bleeding, pneumothorax, or puncture of the brachial plexus. Catheters were flushed with a heparin solution $(10 \mathrm{ml}$ of a $150 \mathrm{IU} / \mathrm{ml}$ solution per lumen) after use or, if not in use, at least once a week. No systemic anticoagulants were given routinely.

The end point of this study was removal of the catheter or death of the patient. Catheters were removed when: (a) they were no longer necessary, (b) there were proven thromboembolic complications-pulmonary embolism, occlusion of the vein by thrombus formation (proven by phlebography or per- 
Table 1. Patient diagnosis.

\begin{tabular}{lc}
\hline Diagnosis & No. of catheters \\
\hline Acute leukemia & 93 \\
Myelodysplastic syndrome & 14 \\
Non-Hodgkin's lymphoma & 7 \\
Multiple myeloma & 3 \\
Other & 6 \\
Total & 123 \\
\hline
\end{tabular}

Table 2. Introduction technique.

\begin{tabular}{llc}
\hline Technique & Vein & No. of catheters \\
\hline Open $(n=80)$ & External jugular & 55 \\
& Internal jugular & 16 \\
& Femoral or great saphenous & 3 \\
& Other & 6 \\
Closed $(n=43)$ & Subclavian & 43 \\
Total & & 123 \\
\hline
\end{tabular}

sistent occlusion of the catheter, in spite of streptokinase infusion), or (c) catheter-related infection was strongly suspected-signs of (local) infection or sepsis without incrimination of any other focus and without response to at least two 48-hour long antibiotic regimens or intensive local therapy (Betadine ${ }^{\circledR}$ ).

Catheter-related infection was considered proven when: (a) fever of $39.5^{\circ} \mathrm{C}$ or more dropped more than $1.5^{\circ} \mathrm{C}$ within 24 hours of catheter removal or (b) cultures from the tip of the catheter were positive in combination with either positive cultures from catheter blood or positive cultures from peripheral blood.

\section{Statistics}

Counts and averages were the main tools applied for the analysis of the data. The actuarial Kaplan-Meier method was used to calculate the proportion of functioning catheters as a function of time. Crosstables were generated to look for possible relationships between diagnosis, first or consecutive catheter, duration of operation, thrombocyte transfusion, perioperative complications, insertion technique, location of catheter insertion, and position of catheter tip on the one hand and duration of catheter function and occurrence of infectious and thromboembolic complications on the other hand.

\section{Results}

One hundred and twenty-three dual lumen catheters were introduced in 101 patients ( 72 men, 51 women) with a mean age of 43 years (range, 15-82 years). Forty-five patients received thrombocyte transfusion. Mean duration of all operations was 63 minutes (standard deviation $=32$ ). The closed technique required significantly less time (51 minutes) than the open technique (70 minutes) $(p<0.001)$.

In 16 insertions $(13.0 \%)$, there were perioperative complications: minor bleeding $(n=13)$, pneumothorax $(n=2)$, and puncture of the brachial plexus without neurological sequel (n $=1$ ). One of the 2 cases of pneumothorax appeared several hours after the operation; both cases needed chest tube drain-
Table 3. Position of tip of catheter.

\begin{tabular}{lrr}
\hline Position & \multicolumn{2}{c}{ No. of catheters } \\
(\%)
\end{tabular}

${ }^{a}$ Excluding 3 catheters inserted inguinally.

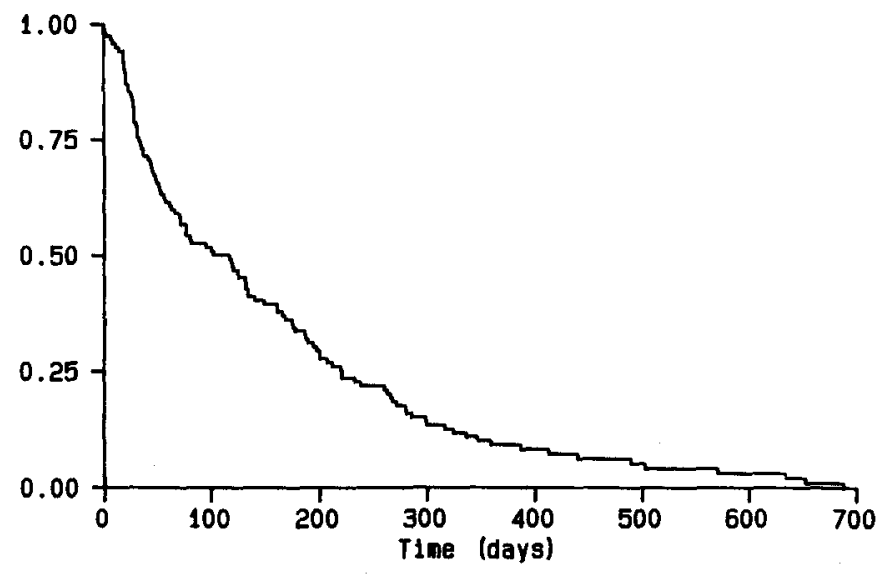

Fig. 1. Actual duration of catheter function.

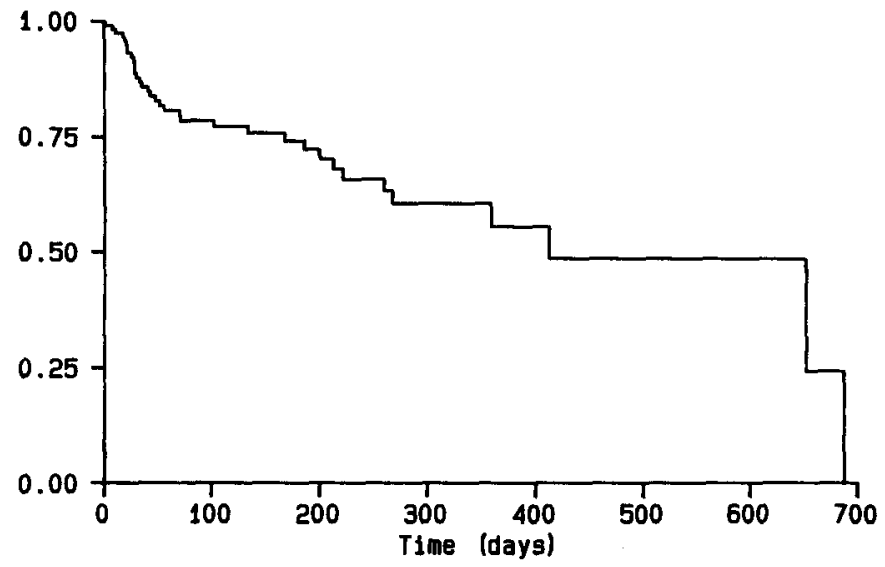

Fig. 2. Projected duration of catheter function without complications, censoring patients who died with a functioning catheter or patients who completed treatment and had the catheter removed.

age. They occurred only in the group with the closed introduction technique ( 43 catheters), giving this complication a $4.6 \%$ occurrence.

Over eighty-five percent of the catheters had an optimal position of the tip: in the vena cava superior or right atrium (Table 3). Mean duration of catheter function was 149 days (range, 0-688 days); after 1 year, $10 \%$ of all catheters were still functioning (Fig. 1). The actuarial probability of complication for functioning of the catheter is shown in Fig. 2. It shows that the 1-year actuarial probability of catheter removal due to complications is equal to $45 \%$. Eighty-seven catheters (70.7\%) functioned without associated complications (Table 4). Forty- 
Table 4. Fate of all catheters.

\begin{tabular}{lrc}
\hline Reason for removal & No. of catheters (\%) \\
\hline No removal: Death of patient & 45 & $(36.6)$ \\
No longer necessary & 39 & $(31.7)$ \\
In situ at conclusion of study & 3 & $(2.4)$ \\
$\quad$ Total uncomplicated & 87 & $(70.7)$ \\
Suspected catheter-related infection & 25 & $(20.4)$ \\
Thromboembolic complication & 5 & $(4.1)$ \\
Combination infection + thromboembolic & 3 & $(2.4)$ \\
Spontaneous dislodgment & 3 & $(2.4)$ \\
Total complicated & $36(29.3)$ \\
Total & $123(100.0)$ \\
\hline
\end{tabular}

Table 5. Duration of catheter function.

\begin{tabular}{lrlc}
\hline Group of catheters & No. of catheters & Mean (days) & Range (days) \\
\hline All catheters & 123 & 149 & $0-688$ \\
Without complications & 87 & 155 & $0-635$ \\
With infections & 28 & 175 & $11-688$ \\
With thrombosis & 8 & 38 & $8-102$ \\
\hline
\end{tabular}

five patients $(36.6 \%)$ died during intensive therapy; none of these deaths was considered catheter-related.

Sixteen catheters $(13.0 \%)$ were removed in the first 31 days because of incorrect placement or early complications. In $29.3 \%$, there were complications leading to removal of the catheter (Table 4). Thirty-nine complications were seen in 36 catheters. Most of these catheters $(n=25)$ were removed because of suspected catheter-related infections, most $(n=23)$ of which only had sepsis. The majority of the infections were caused by Staph. epidermis. Thrombotic complications were as follows: Thrombosis of the host vein $(n=4)$, thrombosis of the catheter $(n=1)$, thrombosis plus sepsis $(n=1)$, infection of the subcutaneous tunnel or exit site plus thrombosis of the vein (n $=1$ ), and infection of the subcutaneous tunnel or exit site and thrombosis of the vein, pulmonary embolisms, and sepsis $(\mathrm{n}=$ 1). Three catheters dislodged spontaneously due to restlessness of the patient. In 26 catheters removed for suspected catheterrelated sepsis, proof of sepsis according to the preset criteria was found in $21(80.8 \%)$. Removal of catheters for proven thromboembolic complications was done significantly earlier ( $p$ $<0.001$ ) than removal for other reasons (Table 5). Crosstables gave no indications of a relationship between perioperative variables and duration of catheter function or late complications.

\section{Discussion}

Only a few studies have been published on dual lumen central venous catheters $[3,4,6,11]$. The group of patients studied here is one that is highly compromised, both during the operation and after, when intensive treatment is performed associated with severe bone marrow depression. This is made apparent by the fact that $36.6 \%$ of the patients died during catheter followup. The high percentage of perioperative bleeding is mainly due to the condition of the patient. A $4.6 \%$ rate of pneumothorax is similar to that seen in other publications [12-15].

Operating times needed here are similar to those found in series for Hickman catheters [16-18]. Our results show the advantage of introducing the catheter through direct puncture of the subclavian vein when compared to the cut-down technique. Both techniques lead to comparable complication rates, both perioperative and long-term as well as comparable duration of catheter function. In all our patients, we therefore prefer the closed technique. We do not consider thrombocytopenia a contraindication for the closed technique, provided these patients are given thrombocyte transfusions before operation. Lately, due to use of image-intensifier x-ray equipment, the whole procedure is often performed within 15-30 minutes.

The duration of catheter function in our study is long when compared to other studies of dual lumen catheters $[3,6,11]$ or to studies of Hickman catheters $[1,2,18-20]$. The large majority of catheters $(70 \%)$ functioned until no longer needed or until the patient died.

Infection remains the greatest diagnostic and therapeutic challenge in patients with hematological malignancies [21], even more so in those having a central venous catheter [6]. We removed $22.8 \%$ of the catheters because of suspected catheterrelated infections. In $80.8 \%$ of the cases of true sepsis, the sepsis could be proven to be catheter-related. The earliest removal for catheter-related infection in our series was after 11 days, whereas the catheter lasting longest was finally removed for suspected catheter-related infection after 688 days. This shows that these infections can only rarely be attributed to surgical introduction of the catheter, but are very often related to the precarious condition of these patients. Rates of catheter removal for suspected catheter-related infections range from $0 \%$ to $23 \%[3,4,6,11]$ in studies of dual lumen catheters and are around $10 \%$ [2] in studies of Hickman catheters. Sanders and associates [19] found dual lumen and single lumen catheters comparable in rates of infection and other complications. The variation of rates of removal for suspected catheter-related infections in all these studies may be a result of patient selection.

Only a few catheters were removed because of proven thromboembolic complications. The real rate of thromboembolic complications may, however, be higher. We did not perform any diagnostic procedures for thrombosis until it was expected on clinical grounds. Other studies [22] indicate that most cases of catheter-related thrombosis are usually not apparent clinically. On the other hand, the problem of a primarily or secondarily infected catheter thrombus is well known from the widely-used single lumen central venous catheters [23, 24]. Part of the infectious complications described as being catheterrelated may, therefore, be primarily thromboembolic complications; however, literature on this subject in silicone rubber catheters is rare [25] and inconclusive. This problem is, therefore, under current (prospective) investigation at our institute.

This evaluation of our experience with this catheter leads us to conclude that the dual lumen silicone rubber catheter is a reliable central venous catheter that can be introduced relatively safely and quickly in highly compromised and thrombocytopenic patients. The closed introduction technique appears to be reliable. The duration of catheter function is long, usually long enough for intensive treatment for acute leukemia as well as for bone marrow transplantation. 


\section{Résumé}

Cent vingt-trois cathéters en caoutchouc siliconé à double lumière ont été mis en place afin de traiter 101 patients ayant une maladie hématologique grave nécessitant une thérapeutique lourde. Le taux de complications péri-opératoires était de $13 \%$. L'étude a comparé 2 techniques d'insertion: avec ou sans abord direct. La durée de l'intervention utilisant la technique sans abord direct (51 minutes en moyenne) était significativement plus courte que celle de la technique avec abord direct (70 minutes) ( $p<0.001$ ), alors que le taux de complications était similaire dans les 2 groupes. Les cathéters sont restés fonctionnels pendant 149 jours en moyenne. Des complications ont nécessité l'ablation du cathéter dans $29.3 \%$ des cas (infection le plus souvent: $20.4 \%$ ). Ensuite, venaient les complications thromboemboliques $(4.1 \%)$, mais, qui survenaient plus tôt dans la période postopératoire $(p<0.001)$. Nos résultats suggèrent que: la technique d'introduction des cathéters par insertion directe dans la veine sous-clavière est rapide et sûre, et ce type de cathéter est bien adapté à l'utilisation de longue durée, à la fois pour perfuser et pour prélever.

\section{Resumen}

Ciento veintrés catéteres venosos centrales de caucho siliconizado fueron colocados en 101 pacientes con neoplasias hematológicas malignas sometidos a tratamiento intensivo. La tasa de complicaciones perioperatorias fue de $13 \%$. Se efectuó la comparación entre las técnicas de inserción abierta y cerrada. El tiempo operatorio utilizado para la inserción del catéter mediante la técnica cerrada (51 minutos en promedio) fué significativamente más corto $(p<0.001)$ que el empleado para la inserción con la técnica abierta ( 70 minutos), en tanto que las tasas de complicaciones fueron iguales. En promedio los catéteres funcionaron durante 149 días. Se presentaron complicaciones que obligaron a su remoción en $29.3 \%$ de los casos, la mayoría relacionada con infecciones relativas al catéter (20.4\%). Las complicaciones tromboembólicas que hicieron necesaria la remoción fueron menos frecuentes $(4.1 \%) \mathrm{e}$ hicieron su aparición considerablemente más pronto $(p<$ 0.001). Estos datos indican que: la inserción del catéter por punción directa de la vena subclavia es un método rápido y seguro, y este tipo de catéter es adecuado para uso a largo plazo, tanto para efectos de la infusión como de muestreo de sangre.

\section{Acknowledgment}

The authors thank Dr. W. Sizoo, hematologist, for advice throughout the study and Dr. S.L. Tjiam, radiologist, for reviewing all of the x-rays.

\section{References}

1. Hickman, R.O., Buckner, C.D., Clift, R.A., Sanders, J.E., Stewart, P., Thomas, E.D.: A modified right atrial catheter for access to the venous system in marrow transplant recipients. Surg. Gynecol. Obstet. 148:871, 1979

2. Press, O.W., Ramsey, P.G., Larson, E.B., Fefer, A., Hickman,
R.O.: Hickman catheter infections in patients with malignancies. Medicine 63:189, 1984

3. Reed, W.P., Newman, K.A., Schimpff, S.C., de Jongh, C.A., Wiernik, P.H.: Dual lumen catheters for angioaccess in patients with leukemia. Am. Surg. 49:373, 1983

4. Raaf, J.H.: Results from 826 vascular access devices in cancer patients. Cancer 55:1312, 1985

5. Kaufman, J.L., Nissenblatt, M.J.: New options for central venous access in cancer chemotherapy: Multiple lumen catheters. Am. Surg. $52: 105,1986$

6. Petersen, F.B., Clift, R.A., Hickman, R.O., Sanders, J.E., Meyers, J.D., Kelleher, J., Dean Buckner, C.: Hickman catheter complication in marrow transplant recipients. J. Parenter. Enter. Nutr. 10:58, 1986

7. Gyves, J., Ensminges, W., Niederhuber, J., Dent, T., Walker, S., Gilbertson, S., Cozzi, E., Saran, P.: A totally implanted injection port system for blood sampling and chemotherapy. J. Am. Med. Assoc. 251:2538, 1984

8. Aker, S.N., Cheney, C.L., Sanders, J.E., Lenssen, P.L., Hickman, R.O., Thomas, E.D.: Nutritional support in marrow graft recipients with single versus double lumen right atrial catheters. Exp. Hematol. 10:732, 1982

9. Heimbach, D.M., Ivey, T.D.: Technique for placement of a permanent home hyperalimentation catheter. Surg. Gynecol. Obstet. $143: 634,1976$

10. Linos, D.A., Mucha, Jr., P.: A simplified technique for the placement of permanent central venous catheters. Surg. Gynecol. Obstet. 154:248, 1982

11. Reilly, J.J., Steed, D.L., Ritter, P.S.: Indwelling venous access catheters in patients with acute leukemia. Cancer 53:219, 1984

12. Pessa, M.E., Howard, R.J.: Complications of Hickman-Broviac catheters. Surg. Gynecol. Obstet. 161:257, 1985

13. Lindblad, B., Wolff, T.: Infectious complications of percutaneously inserted central venous catheters. Acta Anaesth. Scand. 29:587, 1985

14. de Jong, P.C.N., von Meyenfeldt, M.F., Rouflart, M., Wesdorp, R.I.C., Soeters, P.B.: Complications of central venous catheterization of the subclavian vein: The influence of a parenteral nutrition team. Acta Anaesth. Scand. 81[Suppl.]:48, 1985

15. Troxell, M., Mansour, R.: A new technique for placement of tunneled subclavian right atrial catheters: Experience with 130 cases. J. Clin. Oncol. 5:131, 1987

16. Hawkins, J., Nelson, E.W.: Percutaneous placement of Hickman catheters for prolonged venous access. Am. J. Surg. 144:624, 1987

17. Davis, S.J., Thompson, J.S., Edney, J.A.: Insertion of Hickman catheters: A comparison of cutdown and percutaneous techniques. Am. Surg. 50:673, 1984

18. Thomas, P.R.S., Sinnett, H.D.: An evaluation of prolonged venous access catheters in patients with leukemia and other malignancies. Eur. J. Surg. Oncol. 14:63, 1988

19. Sanders, J.E., Hickman, R.O., Aker, S., Hersman, J., Buckner, C.D., Thomas, E.D.: Experience with double lumen right atrial catheters. J. Parenter. Enter. Nutr. 6:95, 1982

20. Reed, W.P., Newman, K.A., de Jongh, C.A., Wade, J.C., Schimpff, S.C., Wiernik, P.H., McLaughlin, J.S.: Prolonged venous access for chemotherapy by means of the Hickman catheter. Cancer 52:185, 1983

21. Bodey, P.B., Rodriguez, V., Chang, H.Y., Narboni, G.: Fever and infection in leukemic patients: A study in 494 consecutive patients. Cancer $41: 1610,1978$

22. Efsing, H.O., Lindblad, B., Mark, J., Wolff, T.: Thromboembolic complications from central venous catheters: A comparison of three catheter materials. World J. Surg. 7:419, 1983

23. Stillman, R.M., Soliman, F., Garcia, L., Sawyer, P.N.: Etiology of catheter-associated sepsis. Arch. Surg. 112:1497, 1977

24. Bozzetti, F., Terno, G., Camerini, E., Baticci, F., Scarpa, D., Pupa, A.: Pathogenesis and predictability of central venous catheter sepsis. Surgery 91:383, 1982

25. Welch, G.W., McKeel, Jr., D.W., Silverstein, P., Walker, H.L.: The role of catheter composition in the development of thrombophlebitis. Surg. Gynecol. Obstet. 138:421, 1974 